\title{
MANEJO PRÉ-ABATE, PARÂMETROS FISIOLÓGICOS DO ESTRESSE E SEUS EFEITOS NA QUALIDADE DA CARNE SUÍNA: REVISÃO
}

\author{
Thuanny Lucia Pereira \\ Anderson Corassa ${ }^{1}$ \\ Angelo Polizel Neto \\ Claudia Marie Komiyama ${ }^{1}$ \\ Rafaeli Gonçalves Leite ${ }^{1}$
}

PEREIRA, T. L.; CORASSA, A.; POLIZEL NETO, A.; KOMIYAMA, C. M.; LEITE, R. G. Manejo pré-abate, parâmetros fisiológicos do estresse e seus efeitos na qualidade da carne suína: revisão. Arq. Ciênc. Vet. Zool. UNIPAR, Umuarama, v. 20, n. 2, p. 101-108, abr./jun. 2017.

RESUMO: As atividades que antecedem o abate exigem um padrão e ainda algumas mudanças que priorizem em particular o bem-estar do animal. Dessa forma, o bem-estar na espécie suína assume grande importância quando se observa o manejo da granja ao frigorífico correlacionando com a atuação de fatores estressores que implicam em perdas tanto aos produtores quanto à indústria frigorífica. As falhas no manejo pré-abate podem resultar em carcaças com desvios, como carne pálida, flácida e exsudativa (PSE) e carne escura, firme e seca (DFD). Para assegurar o bem-estar e obter carne suína de qualidade é necessário que o manejo pré-abate seja realizado de forma adequada considerando as características comportamentais e fisiológicas dos animais, que se trata do ajuste com o ambiente e com os indivíduos, estabelecendo uma harmonia entre homem e animal. Em função do que foi relatado, objetivou-se revisar os fatores que interferem no manejo pré-abate de suínos e suas influências sobre os indicadores de estresse e qualidade da carne. O manejo pré-abate deve ser estabelecido conforme padrões conhecidos, no entanto, existe a necessidade de rever cada procedimento e estabelecer estudos regionais que envolvam todos os procedimentos, desde o embarque até o período de espera dos suínos na indústria frigorífica.

PALAVRAS-CHAVE: Bem-estar. Comportamento. Desembarque. Embarque. Transporte.

\section{PRE-SLAUGHTER MANAGEMENT, PHYSIOLOGICAL PARAMETERS OF STRESS AND ITS EFFECTS ON PORK QUALITY: REVIEW}

\begin{abstract}
The activities that take place before slaughtering require a standard and also a few changes prioritizing the animal's welfare. Thus, the wellness of pigs is very important when analyzing their handling from the farm to the slaughterhouse, correlated with the stressing factors that imply in losses to both the producers and the meat industry. Flaws in the pre-slaughter management can result in carcasses presenting deviations, such as pale, limp and exudative (PSE) meat, and dark, firm and dry (DFD) meat. In order to ensure the well-being and obtain a quality pork meat, the pre-slaughter management must be appropriately carried out, considering the behavioral and physiological characteristics of the animals. Such characteristics are related to both the environment and the individuals, establishing harmony between humans and animals. Therefore, this paper aimed to review the factors interfering in the pre-slaughter management of pigs and their influence on stress indicators and meat quality. The pre-slaughter management must follow known standards; however, each procedure must be reviewed, developing regional studies involving all procedures, from shipping to the waiting period of the animals at the slaughterhouses.
\end{abstract}

KEYWORDS: Behavior. Shipping. Transportation. Unloading. Welfare.

\section{MANEJO PRE MATANZA, PARÁMETROS FISIOLÓGICOS DEL ESTRÉS Y SUS EFECTOS SOBRE LA CALIDAD DE LA CARNE DE CERDO: REVISIÓN}

RESUMEN: Las actividades que anteceden la matanza exigen un estándar y aún algunos cambios que prioricen en particular el bienestar del animal. Así, el bienestar en la especie porcina es de gran importancia cuando se observa el manejo de la granja al matadero, correlacionando con la actuación de factores de estrés que implican en pérdidas tanto a los productores como a la industria frigorífica. Las fallas en el manejo pre matanza pueden resultar en caparazones con desvíos, como carne pálida, flácida y exudativa (PSE), y carne oscura, firme y seca (DFD). Para asegurar el bienestar y obtener carne porcina de calidad es necesario que el manejo pre matanza sea realizado de forma adecuada, considerando las características comportamentales y fisiológicas de los animales, pues se trata del ajuste con el ambiente y con los individuos, estableciendo armonía entre hombre y animal. De acuerdo a lo informado, se ha buscado revisar los factores que interfieren en el manejo pre matanza de porcinos y sus influencias sobre los indicadores de estrés y calidad de la carne. El manejo pre matanza debe ser establecido conforme estándares conocidos, sin embargo, existe la necesidad de revisar cada procedimiento y establecer estudios regionales que involucran todos los procedimientos, desde el embarque hasta el periodo de espera de los porcinos en el matadero.

PALABRAS CLAVE: Bienestar. Comportamiento. Desembarque. Embarque. Transporte.

DOI: 10.25110 /arqvet.v20i2.2017.5233

1Programa de Pós-Graduação em Zootecnia da Universidade Federal do Mato Grosso (UFMT). Email: anderson_corassa@ufmt.br 


\section{Introdução}

O Brasil tem se firmado como um grande fornecedor mundial de carnes, sendo o quarto maior produtor de carne suína do mundo com 3.370 mil toneladas de carcaça suína, estando altamente concentrado nas regiões sul, sudeste e centro-oeste do país. A cadeia suinícola é responsável pelo desenvolvimento econômico e social de muitos municípios, gerando neste setor muitos empregos (ABIPECS, 2013). Neste cenário, a condição pré-abate apresenta perfis distintos em cada região devido, entre outros fatores, ao tempo de jejum, às condições de embarque e desembarque, ao período de descanso pós-transporte, e à duração, distância e densidade praticadas com os animais da granja ao frigorífico (KOHLER; FREITAS, 2005; DALLA COSTA et al., 2007; ARAÚJO, 2009). Para assegurar o bem-estar e obter carne suína de qualidade é preciso proceder todos os passos do manejo com os animais de forma adequada considerando suas características comportamentais, a harmonia entre homem e animal, a partir do entendimento de que o bem-estar trata-se da capacidade do animal em se ajustar ao ambiente, ao estado em que os animais se encontram e à qualidade de vida deles (BAPTISTA; BERTANI; BARBOSA, 2011).

Quando os animais são condicionados a situações estressantes, desenvolvem respostas fisiológicas e comportamentais ao novo ambiente ou manejo (LUDTKE et al., 2012). Sendo assim, objetiva-se com este trabalho, revisar os fatores que interferem o manejo pré-abate de suínos, e suas influências sobre aspectos de bem-estar animal, parâmetros fisiológicos do estresse e qualidade da carne.

\section{Desenvolvimento}

\section{Manejo pré-abate}

O manejo pré-abate compreende uma série de atividades realizadas como jejum na granja, embarque, transporte (KOHLER; FREITAS, 2005; KEPHART; HARPER; RAINES, 2010), desembarque, alojamento nas baias do frigorífico, descanso (DALLA COSTA et al., 2008; DALLA COSTA et al., 2010) até a insensibilização dos suínos no frigorífico (DALLA COSTA et al., 2006; ARAÚJO, 2009). As atividades que antecedem o abate necessitam de cuidados especiais no intuito de manter os parâmetros fisiológicos em níveis normais com intuito de promover o bem-estar (LI et al., 2008) e podem alterar a qualidade da carcaça e da carne (KOHLER; FREITAS, 2005; MALENA et al., 2007). As alterações conhecidas são: carne dura, escura e seca (DFD) ou carne pálida, mole e exsudativa (PSE) que produzem grandes perdas econômicas (SANTANA et al., 2009). A carne ideal RFN (Reddish Pink, Firm, Non-exudative - avermelhada ou rosa, firme e não exsudativa), permite mais um desvio além dos citados anteriores como RSE (Reddish Pink, Soft, Exudative - carne avermelhada ou rosa, flácida e exsudativa).

\section{Jejum}

O jejum pré-abate é um procedimento realizado no final da fase de terminação de suínos e perdura até o abate, consiste nos animais não terem acesso a alimentos sólidos, ração, por um determinado período e ter acesso livre à água
(ARAÚJO, 2009). Esse manejo não deve apresentar influência negativa principalmente em relação ao bem-estar dos animais durante o período pré-abate, sendo fundamental por contribuir para economia de ração, reduzir o volume de dejetos, a mortalidade no transporte (DALLA COSTA et al., 2008; DALLA COSTA et al., 2010), promover a melhora na segurança alimentar, diminuindo o risco de extravasamento do conteúdo intestinal bem como na proliferação de bactérias patogênicas por meio das fezes, (DALLA COSTA et al., 2008; RITTER et al., 2009), e no estabelecimento do padrão de peso, uniformização e rendimento de carcaças, já que produtores são remunerados por mérito de carcaça e os consumidores almejam qualidade da carne suína (ARAÚJO, 2009).

O tempo de jejum na granja se inicia com a interrupção do acesso dos suínos aos alimentos sólidos até o momento do embarque. O período de jejum total segue durante todo o transporte e é acrescido do período de espera nas áreas de descanso do frigorífico até o momento do abate. Sob o ponto de vista fisiológico, existe uma recomendação quanto ao tempo de jejum total entre 16 e 24 horas (SILVEIRA, 2010). Porém, existe uma grande variação vinculada à logística do frigorífico (ARAÚJO, 2009; DALLA COSTA et al., 2010).

Não há consenso em relação à duração do jejum alimentar em suínos. Murray (2000) recomenda entre 10 e 24 horas, Kohler e Freitas (2005) utilizaram o período de jejum de 12 a 18 horas em seus experimentos. Este período tem variado, segundo Dalla Costa et al. (2010), de acordo com o país e com o perfil genético dos suínos, que recomendam um jejum entre 12 e 18 horas antes do embarque e não mais do que 24 horas de jejum total.

Com o objetivo de obter maior porcentagem de suínos com menor peso estomacal, Dalla Costa et al. (2008) sugerem um período de jejum na granja de 15 horas. Segundo Murray (2000), a perda de peso se torna contínua em uma taxa de 0,12 a $0,20 \%$ por hora até o limite de $5 \%$ em 24 horas e com perdas na carcaça de 0,06 para $0,14 \%$ por hora. Períodos superiores a 24 horas proporcionam uma perda na carcaça de aproximadamente $100 \mathrm{~g}$ /hora, além de atuar como um potente fator estressante (ARAÚJO, 2009), isso pode ser evidente devido a secreção de cortisol se tornar contínua e sustentada, porém as respostas a situações ou agentes estressores adicionais como densidade, transporte, são observadas com menor amplitude, porque existe um limite fisiológico natural (DALLA COSTA et al., 2008). O tempo de jejum pode afetar diretamente a qualidade da carne suína, assim quando não acontece de forma adequada pode interferir nas reservas de glicogênio muscular, resultando em carnes PSE e DFD, resultados de interações entre o genótipo e o ambiente (BRIDI et al., 2003; BERTOLONI et al., 2006).

Jejum prolongado associado com manejo pré-abate inadequado, reduz o nível de carboidrato e aumenta a incidência de carne DFD, especialmente nos músculos como Adductor e Semispinali capitis (ARAÚJO, 2009).

O tempo de jejum influencia as outras condições do estresse do transporte, e pode interferir de modo negativo no bem-estar, no perfil hormonal dos animais condicionados, afetando os níveis sanguíneos de cortisol, lactato, creatinina fosfoquinase (CPK) e sua frequência cardíaca (PÉREZ et al., 2002; DALLA COSTA et al., 2008). Dalla Costa et al. (2008) avaliaram o tempo de jejum na granja de $9,12,15$ e 18 horas e verificaram que suínos com 18 horas de jejum apresenta- 
ram menor variação no cortisol na saliva durante as etapas do manejo pré-abate em comparação com os demais períodos de jejum, e que para reduzir seus valores antes do abate deve-se promover maior tempo de descanso no frigorífico para os animais. Salmi et al. (2012) analisaram diferentes tempos de jejum e sua influência na qualidade da carne suína e os resultados mostraram que o $\mathrm{pH}$ aumentou conforme aumentou o tempo de jejum e que diminuiu a perda por gotejamento no músculo Longissimus dorsi.

\section{Embarque}

O embarque juntamente com o desembarque é considerado ponto crítico do manejo pré-abate, por haver maior contato humano-animal e pela usual falta de um manejo racional adequado (DALLA COSTA et al., 2006; ARAÚJO, 2009).

No Brasil, a preocupação com o sistema de condução dos animais até o caminhão em relação ao bem-estar e a qualidade da carne tem sido muito restrita (DALLA COSTA et al., 2007). Correa et al. (2010) observaram que o pH final e valores de $\mathrm{L}^{*}$ foram maiores e menor, respectivamente, para o músculo Semimembranoso em suínos conduzidos por choque elétrico em comparação com os conduzidos por raquete. De acordo com diversos estudos, a condução dos suínos deve seguir um programa de manejo racional por pessoas com treinamento especializado, com tranquilidade, sem a utilização de bastão elétrico de forma aversiva e com o auxílio de uma tábua de manejo.

Aspectos fisiológicos, sanitários, produtivos e comportamentais podem ser avaliados para caracterizar embarques que sejam realizados respeitando os animais. A observação do comportamento é um método rápido e prático quando se avalia o bem-estar animal, sendo possível mensurar a parte do organismo que interage com o ambiente (BAPTISTA; BERTANI; BARBOSA, 2011). Nos estudos de Correa et al. (2010), observaram-se suínos sendo conduzidos com choque elétrico durante o embarque apresentando maior número de quedas e de comportamento de monta em relação a condução por raquete e ar comprimido, além de grande quantidade de lesões de pele, bem como maior número de animais cansados, maiores concentrações de lactato no plasma e presença de hemorragia nos músculos.

Na caracterização da rampa do embarcadouro, o ângulo de inclinação parece exercer influência sobre a dinâmica do embarque e sobre os animais. Kephart, Harper e Raines (2010) relataram que a subida de suínos em rampas de transporte provavelmente pode causar um distúrbio psicológico e um aumento na frequência cardíaca a um nível de arritmia. A frequência cardíaca pode sinalizar perda do bem-estar animal, por se ajustar conforme a situação emocional, e assim as elevadas frequências cardíacas são resultados de atividades físicas excessivas, reações de defesa e alarme ou pelo aumento da temperatura corporal (BAPTISTA; BERTANI; BARBOSA, 2011).

Pesquisas diferem quanto a recomendação da melhor inclinação de rampa, como Pérez et al. (2002), reporta o uso de rampas com inclinação de $15^{\circ}$, já Ritter et al. (2007a) e Kephart, Harper e Raines (2010) recomendaram rampas de 8 a $10^{\circ}$.

No embarque os animais são submetidos a ambien- tes distintos, promovendo estresse, que é resultado das etapas do processo de transporte. Os animais que expressam sinais de estresse como dificuldade respiratória, cianose, tremores musculares, vocalização e elevada temperatura corporal são referenciados comumente como "cansados" (PILCHER et al., 2011).

Os aumentos de vocalizações são muitas vezes utilizados como indicadores de dor ou sofrimento (BAPTISTA; BERTANI; BARBOSA, 2011). Isso foi observado por Correa et al. (2010), que verificaram que os suínos conduzidos no embarque por bastão elétrico apresentam vocalização $(9,5$ $\pm 1,8)$ vezes maior de do que com raquete $(4,5 \pm 1,8)$ e ar comprimido $(5,4 \pm 1,8)$. A última etapa após o embarque dos animais no caminhão é o banho de aspersão quando a temperatura for superior a $10^{\circ} \mathrm{C}$, molhando os animais após o carregamento e antes de iniciar o transporte (LUDTKE et al., 2012).

\section{Transporte}

O transporte é um componente visível na indústria de produção de suínos, sendo uma atividade estressante para os suínos, por expor os animais a ruídos, cheiros desconhecidos, alterações de velocidade brusca do caminhão, diferentes temperaturas ambientais, vibrações, menor espaço social, individual e a interação com o homem, tais fatores levam a respostas comportamentais e fisiológicas que podem contribuir para redução do rendimento de carcaça e qualidade da carne, bem como no bem-estar animal (LI et al., 2008). Baseado na variação do cortisol salivar, durante o manejo pré-abate, Schwartzkopf-Genswein et al. (2012), concluíram que o transporte é o momento de maior intensidade de estresse nos suínos em todo o período pré-abate. A eficiência do transporte de animais, que envolve o recolhimento de animais em várias fazendas, filas e desembarque nos frigoríficos, pode provocar interações com o processo de planejamento do transporte, condições das estradas, duração do transporte e distâncias percorridas (ARADOM, 2012).

Uma pesquisa dos Estados Unidos entre o ano de 2000 e 2007 relataram que dos suínos destinados ao abate, $0,25 \%$ morreram durante o transporte e cerca de $0,44 \%$ apresentaram-se injuriados à chegada da planta frigorífica (RITTER et al., 2008b). No leste do Canadá, a proporção de mortos no transporte no ano de 2010 apresentava 13.000 suínos $(0,08 \%)$, que significaram um prejuízo de US\$ 4 milhões (SCHWARTZKOPF-GENSWEIN et al., 2012). A mistura de grupos sociais distintos na mesma baia induz um aumento nos níveis de agressão em função do estabelecimento de uma nova hierarquia social. Esse tipo de comportamento que envolve interações agonísticas pode gerar escoriações na pele, bem como defeitos na qualidade da carne e afetando o bem- estar animal (BAPTISTA; BERTANI; BARBOSA, 2011).

Schwartzkopf-Genswein et al. (2012) relataram um aumento de carne PSE em suínos transportados no compartimento frontal superior, em veículos norte americanos, que provavelmente esta relacionado com a necessidade de esforço físico dos suínos no momento do embarque. Dalla Costa et al. (2010) reportaram que os animais localizados na posição anterior do caminhão ficam submetidos a elevadas temperaturas e nos box posteriores estão sujeitos a vibrações, impactos pelos eixos de sustentação do rodado. 
A atitude do motorista tem efeito no estresse dos animais durante o transporte. Isso porque a qualidade do transporte pode ser influenciada pela habilidade do motorista, o estilo de direção e o nível de estresse do mesmo (COCKRAM et al., 2004).

Kephart, Harper e Raines (2010), realizaram observações em 41.744 suínos destinados ao abate durante o transporte até a unidade frigorífica em diferentes tipos de veículos, e relataram que a porcentagem de animais com dificuldade respiratória foram: potbelly $(2,99 \%)$, straight $(1,62 \%) \mathrm{e}$ straight wide $(0,66 \%)$. Esses autores verificaram que no tipo de veículo potbelly, veículo bem compartimentado, os suínos estavam condicionados a caminhar por diversas rampas dentro do veículo com inclinação de $20^{\circ}$, e por isso apresentavam ofegantes após o transporte em comparação aos demais tipos de veículo com plataformas hidráulicas.

Ritter et al. (2008b), enfatizaram que os tipos de veículos de transporte da América do Norte incorporam múltiplos andares e rampas internas de inclinação de até $40^{\circ}$, o que resulta na dificuldade de realizar o carregamento e descarregamento, e promovendo assim o aumento da utilização de bastão elétrico em até $32 \%$.

\section{Duração e distância do transporte}

No transporte de suínos ao abate existem duas características importantes que correspondem à distância percorrida e o tempo decorrido entre o carregamento na granja e o alojamento nas baias de descanso na unidade frigorífica (DALLA COSTA et al., 2010). Sutherland et al. (2012) concluíram com base em uma revisão que os níveis críticos de cortisol e outros parâmetros fisiológicos que indicam estresse elevado nos animais em transporte se dão nas primeiras 12 horas de transporte.

Segundo levantamento apresentado por Schwartzkopf-Genswein et al. (2012), nos Estados Unidos, 51,8\% dos suínos comerciais foram transportados menos de 161 $\mathrm{km}, 32,6 \%$ foram transportados entre 162 e $322 \mathrm{~km}$, e $15,6 \%$ foram transportados mais de $323 \mathrm{~km}$, no ano de 2003 . Resultados semelhantes foram encontrados por Souza e Corassa (2012), em que 38,87\% dos suínos produzidos no Estado do Mato Grosso foram transportados em distâncias entre $100 \mathrm{e}$ $200 \mathrm{~km}$, ao considerar o fluxo de animais entre 2008 a 2011.

O tempo total de transporte apresenta grande variação por estar relacionado com as condições da topografia das estradas entre a granja e o frigorífico. O tempo de transporte total de oito a 16 horas mesmo sem acesso a água, parece ser aceitável sob o ponto de vista de bem-estar animal. Viagens longas, acima de 24 horas faz-se o uso de adequada ventilação e densidade e que possua água disponível (SILVEIRA, 2010). Quando em períodos de transporte superiores a esses, os animais devem ser desembarcados, descansados por 24 horas e receber ração antes da continuidade do percurso (EC, 2005).

CARR et al. (2008), avaliando o tempo de transporte de 45 minutos a três horas, concluíram que suínos devem ser transportados no período menor que três horas quando a temperatura ambiente for $\leq 22^{\circ} \mathrm{C}$ para reduzir o estresse e melhorar a qualidade da carne. Com isso, em viagens de curta duração os suínos são mais difíceis de manejar e podem produzir carne de qualidade inferior em comparação a longas viagens (Schwartzkopf-GENSWEIN et al., 2012). Salmi et al. (2012), observaram que o pH inicial e final da carne suína em diversos estudos aumentou com longas durações de transporte, já que longas viagens acarretam maior depleção do glicogênio muscular, no qual causa o aumento no $\mathrm{pH}$ final da carne.

De acordo com a programação de abate a duração do transporte de suínos pode aumentar, já que existem sistemas de produção de suínos mais distantes da unidade frigorífica (ARAÚJO, 2009).

Schwartzkopf-Genswein et al. (2012), revisando trabalhos sobre o transporte de suínos relatou que a maioria das pesquisas têm conduzido o tempo de transporte de duas a quatro horas. Por sua vez, Averos et al. (2009), afirmam que viagens que excedam duas horas permite ao animal se recuperar do esforço físico inicial e melhor manejá-los. Salmi et al. (2012), observaram que com o aumento da duração do transporte (até 24 horas), independente de outras variáveis como jejum e período de descanso, os suínos provavelmente aumentaram a demanda de energia e o estresse físico, o que difere de Sutherland et al. (2012) que encontraram um menor percentual de animais cansados e feridos em longas viagens (acima de 11 horas).

\section{Densidade}

Pesquisas apontam que densidade inadequada no transporte pode resultar em lesões na pele (PILCHER et al., 2011), interferir nos parâmetros da qualidade da carne (CHAI et al., 2010), nos constituintes sanguíneos (WILIAMS et al., 2008), mortalidade durante o percurso (WARRIS et al., 1998; RITTER et al., 2008) e alterações comportamentais e fisiológicas (KIM et al., 2004; SUTHERLAND et al., 2009). Alta densidade pode resultar em uma viagem desconfortável, uma vez que o espaço limitado impede os animais de se posicionar de forma livre e assim o equilíbrio torna-se difícil, especialmente em longas distâncias (MIRANDA-DE LA LAMA et al., 2014).

As recomendações quanto à densidade apresentam variabilidade de acordo com cada país, e devem ser adequadas seguindo as condições de transporte como topografia das estradas, distância da granja ao frigorífico, condições climáticas, material genético e peso dos suínos (SILVEIRA, 2010). Ritter et al. (2007), observaram que o aumento da área por animal no transporte de 0,396 para $0,462 \mathrm{~m}^{2} /$ suíno reduziu o total de perdas no transporte.

A diretiva de proteção animal European Comission recomenda que a densidade de transporte deve ser em torno de $0,425 \mathrm{~m}^{2} / 100 \mathrm{~kg}$ de suínos ou $235 \mathrm{~kg} / \mathrm{m}^{2}$, em que requer espaço para os suínos deitar ao mesmo tempo, não resultando em alterações comportamentais durante o transporte (EC, 2005). Essa orientação permite um aumento máximo de $20 \%$ de acordo com o tempo de transporte e as condições climáticas. Barton-Gade e Christensen (1998) aplicando a densidade de 0,42 e $0,50 \mathrm{~m}^{2} / 100 \mathrm{~kg}$ observaram que os animais apresentaram dificuldade de manter o equilíbrio.

Pilcher et al. (2011) avaliaram o efeito do tempo de transporte curto $(<1 \mathrm{~h})$ e longo (três horas) em relação as densidades 0,$396 ; 0,415 ; 0,437 ; 0,462 ; 0,489$ e $0,520 \mathrm{~m}^{2} / \mathrm{su}-$ íno, e observaram que nas densidades de 0,415 e $0,437 \mathrm{~m}^{2} /$ suíno a incidência de animais cansados foi maior em curtas 
do que longas distâncias em relação as demais densidades. A incidência de animais ofegantes foram maiores nas densidades menores $(0,396 ; 0,415 ; 0,437)$ em curtas viagens, porém nas demais densidades $(0,462 ; 0,489$ e 0,520$)$ não obtiveram efeito. Contudo, Kephart, Harper e Raines (2010), em um frigorífico de suínos nos Estados Unidos não encontraram efeito no tempo de transporte e na densidade com relação a incidência de animais ofegantes após o descarregamento na indústria.

Kephart, Harper e Raines (2010) constataram maior percentual de animais com lesões $(2,30 \%)$ em viagens curtas (menor que 2,5 h) com densidades elevadas $(\geq 260 \mathrm{~kg}$ / $\mathrm{m}^{2}$ ). Esse resultado condiz com a relutância dos suínos em se deitar em curtos períodos de transporte associada a uma alta densidade que acarreta desconforto e aumento do percentual de problemas locomotores. Ritter et al. (2006) registraram um menor percentual de animais cansados após a chegada da unidade frigorífica quando reduziram a densidade de 0,62 a 0,27\% (330 para $269 \mathrm{~kg} / \mathrm{m}^{2}$ ). Conforme os estudos de Chai et al. (2010) aplicando a densidade de $275 \mathrm{~kg} / \mathrm{m}^{2}$ observaram os animais mais tranquilos e deitados ao longo do transporte.

Baixas densidades podem causar escoriações e lesões corporais produzidas por agressividade entre os suínos e choque com a carroceria (BARTON-GADE; CHRISTENSEN, 1998), por outro lado altas densidades (0,30 a $0,31 \mathrm{~m}^{2} / 100 \mathrm{~kg}$ ) apresentam a enzima creatina fosfoquinase (CPK) aumentada, pelo estresse físico que pode causar mortalidade devido à sobrecarga do sistema cardiovascular (WARRISS et al., 1998).

A aplicação da densidade adequada se torna ideal para acomodação dos suínos e que tanto em alta como baixa densidade no transporte de suínos afetam negativamente a qualidade da carne.

\section{Desembarque}

O manejo de desembarque deve ser conduzido com tranquilidade, e com uso de tábua de manejo; evitando assim a condução rápida, agressiva e com uso de choques, manejos que contribuem para o aumento na produção de carnes exsudativas (RITTER et al., 2008; DALLA COSTA et al., 2010). Quando existe grande número de caminhões para descarga dos suínos, alguns veículos devem ficar no local de espera, que deve ser protegido de intempéries do tempo. Esse tempo de espera dos animais dentro do caminhão, quando inadequado, compromete o bem-estar animal, já que o sistema de ventilação fica comprometido, e os animais aumentam a frequência respiratória devido ao estresse térmico, mecanismo de resposta na manutenção da termorregulação (BAPTISTA; BERTANI; BARBOSA, 2011). Informações referentes ao tempo de espera para o desembarque foram coletadas por Araújo (2009), ao avaliar quatro unidades frigoríficas observou diferença significativa, em que nos frigoríficos A e B houve o maior tempo de espera (87,93 e 72,04 minutos), ou seja, maior demora para proceder a etapa de desembarque comparado aos tempos nos frigoríficos $\mathrm{C}$ (35,50 minutos) e D (43,24 minutos). A logística da indústria frigorífica deve adequar o horário de carregamento na granja, distância percorrida, número de suínos transportados, tempo de transporte que associado ao número de plataformas e de colaboradores no desembarque reduziria o tempo de espera e contribuiria para o bem-estar animal (ARAÚJO, 2009).

O tempo de desembarque é bastante variável, podendo estender de minutos a várias horas. Kephart, Harper e Raines (2010) observaram maior tempo de descarga nos caminhões do tipo potbelly (17,3 minutos) que aqueles dos tipos straigh-deck (12,4 minutos) e straight wide (10,3 minutos), devido à existência de maior número de rampas internas para a saída do veículo transportador. Esses dados confirmam com os achados de Ritter et al. (2008) que também observaram tempo de descarregamento prolongado no tipo de caminhão potbelly em relação ao demais veículos transportadores norte americanos.

No desembarque também existe uma forte interação homem-animal, e a necessidade de se obter o conhecimento do comportamento do suíno é muito importante, por existir a dificuldade de suínos descerem por rampas com inclinações superiores a 15 ou $20^{\circ}$ (DALLA COSTA et al, 2008). Esse manejo torna-se mais difícil quando há utilização de varas, choques e gritos. $\mathrm{O}$ uso de choques durante o desembarque dos suínos nas baias de espera é permitida na porcentagem de $25 \%$ nos membros, porém ocorre a utilização exacerbada o que resulta em carcaças com hematomas, equimoses e ferimentos (ARAÚJO, 2009).

Ritter et al. (2006) monitoraram 25 suínos que apresentavam cansados durante o carregamento e verificaram que $72 \%$ desses suínos estavam normais durante o descarregamento na indústria após três horas de viagem. Entretanto, parâmetros metabólicos de suínos cansados durante a descarga foram mensurados por Ritter et al. (2009) que em comparação com suínos normais apresentaram elevado níveis de lactato no sangue, amônia, sódio, potássio, cortisol, epinefrina e concentrações de noradrenalina enquanto baixo pH sanguíneo, bicarbonato, dióxido de carbono e valores de insulina, concluindo que os suínos feridos apresentavam quadro de acidose metabólica.

\section{Período de descanso}

Após o desembarque dos animais no frigorífico, estes são alojados nas baias de espera. As baias de espera devem possibilitar a recuperação do desgaste físico e do estresse ocorrido no transporte, bem como auxilia na manutenção da velocidade constante da linha de abate (DALLA COSTA et al., 2006). Dalla Costa et al. (2007) relataram que os suínos permaneceram em descanso por três horas, e correlaciona que períodos curtos não interferiram no rendimento de carcaça quente e no peso dos suínos. Araújo (2009) em uma coleta de dados em três frigoríficos reportou que o menor tempo de descanso foi no frigorífico A (seis horas), e o demais frigoríficos mantiveram os suínos nas bai as de espera por cerca de 13 horas. A explicação para a variação nesse período está relacionada com a capacidade de abate das unidades frigoríficas, número de animais, tempo de transporte, condições ambientais e principalmente pela logística de cada local.

Para tanto, o tempo de descanso é fundamental para recuperação das reservas do glicogênio e possibilitar a produção de carcaças de boa qualidade. Warriss et al. (1998) reportaram que suínos que descansaram por longos períodos apresentaram menor peso de carcaça quente em relação aos suínos submetidos a períodos curtos de descanso ( $\leq 1$ e 3 horas). Dalla Costa et al. (2006) verificaram que a variação de 3 
a 9 horas no período de descanso no frigorífico não afetou a perda de peso corporal, bem como o peso do estômago cheio e vazio, o peso do conteúdo estomacal e o escore de lesão na mucosa esofágica gástrica.

Ludtke et al. (2012) recomendaram o período de descanso de seis horas em viagens de curta duração associado aos manejo adequado de embarque e desembarque para que não houvesse interferência na qualidade da carne dos suínos. Novas iniciativas da regulamentação de bem-estar animal sugerem que ocorra maior período de descanso dos animais no veículo após longas jornadas do que após o descarregamento (BORELL; SCHAFFER, 2005). Essas informações são compatíveis com os achados de Lewis e Berry (2006) em que observaram maior frequência de repouso de suínos transportados entre 13 e 24 horas $(91,5 \%)$ do que aqueles entre uma e doze horas $(59,8 \%)$.

Os suínos devem ser condicionados as baias de descanso em pequenos grupos, 10 a 15 animais, ou em grandes, 200 animais por baia. Na indústria frigorífica, assim como no veículo transportador, não deve misturar lotes de suínos devido à dimensão das instalações e ao aumento de brigas, o que promove incremento dos escores de lesões, prejudicando o bem-estar animal e a qualidade da carne (ARAÚJO, 2009). Nanni Costa et al. (2002) encontraram valores médios menores de $\mathrm{pH}$ inicial e final em suínos submetidos ao período de descanso inferior a duas horas. Esses dados podem estar relacionados com as reservas de glicogênio e presença de ácido láctico.

Os suínos apresentam comportamentos distintos quando submetidos em baias de espera, isso pode estar relacionado ao número de suínos/baia, método de condução, número de colaboradores, entre outros. Araújo (2009) observou os comportamentos nas baias de espera de quatro frigoríficos no sul do país, e registrou uma elevada porcentagem de suínos que permaneceram em pé, na primeira hora de avaliação, sendo que a maior porcentagem de suínos em pé foi observada nas baias de espera dos frigoríficos A $(73,73 \%)$ e B $(60,21 \%)$, diferindo dos valores encontrados nos frigoríficos C $(33,74)$ e D $(40,07 \%)$. Isso caracterizou que nas primeiras horas, os suínos apresentavam expostos a novos ambientes, ruídos, cheiros e interação com outros colaboradores, o que torna os suínos em Estado de alerta e movimentação. Já no frigorífico $\mathrm{C}$ e $\mathrm{D}$, houve uma alta incidência de animais deitados nas primeiras horas, devido os suínos provavelmente buscaram posições de conforto, devido a situação de estresse e cansaço maior com relação aos manejos anteriores.

Salmi et al. (2012), avaliando animais que permaneceram cerca de 15 minutos nas baias de espera do frigorífico em comparação com animais que permaneceram 24 horas, observaram menor pH do músculo Semimembranosus.

\section{Considerações finais}

As condições do manejo pré-abate são de grande importância por influenciar na qualidade da carne produzida, no bem-estar animal e nos parâmetros fisiológicos. Com essa visão exigir um padrão quanto ao transporte de animais, reduziria os desvios de carnes como PSE e DFD. Quanto ao bem-estar animal deve ser adequado na produção de suínos, porém ainda esse tema é recente e requer pesquisas e estudos na área.

\section{Referências}

ABIPECS. Produção mundial de carne suína 2013.

Disponível em: <http://www.abipecs.org.br/pt/estatisticas/ mundial/producao-2.html>. Acesso em: 10 fev. 2015.

ARADOM, S. Animal transport and welfare with special emphasis on transport time and vibration including logistics chain and slaughtherhouse operations. Acta Universitatis Agriculturae Sueciae, v. 98, 2013.

\section{ARAÚJO, A. P. Manejo pré-abate e bem-estar dos} suínos em frigoríficos brasileiros. 2009. 139f. Dissertação (Mestrado em Medicina Veterinária) - Faculdade de Medicina Veterinária e Zootecnia, Universidade Estadual Paulista, Botucatu.

AVEROS, X. et al. Effect of the duration of commercial journeys between rearing farms and growing-finishing farms on the physiological stress response of weaned piglets. Livestock Science, Denmark, v. 122, p. 339-344, 2009.

BAPTISTA, R. I. A. A.; BERTANI, G.R.; BARBOSA, C. N. Indicadores do bem-estar em suínos. Ciência Rural, Santa Maria, v. 41, n. 10, p. 1823-1830, 2011.

BARTON-GADE, P.; CHRISTENSEN, L. Effect of different stocking densities during transport on welfare and meat quality in Danish slaughter pigs. Meat Science, Australia, v. 48, p. 237-247, 1998.

BERTOLONI, W. et al. Avaliação de diferentes híbridos suínos submetidos à insensibilização elétrica e gasosa (CO2). Parte 2 - mensuração objetivas de qualidade.

Ciência e Tecnologia de Alimentos, Campinas, v. 26, n. 3, p. 564-570, 2006.

BORELL, E. V.; SCHAFFER, D. Legal requirements and assessment of stress and welfare during transportation and pre-slaughter handling of pigs. Livestock science, Denmark, v. 97, p. 81-87, 2005.

BRIDI, A. M. et al. Efeito do genótipo halotano e de diferentes sistemas de produção na qualidade da carne suína. Revista Brasileira Zootecnia, Viçosa, v. 32, n. 6, p. 1362-1370, 2003.

CARR, C. C. et al. Effects of slaughter date, on-farm handling, transport stocking density, and time in lair age on digestive tract temperature, serum cortisol concentrations, and pork lean quality of market hogs. The Professional Animal Scientist, Columbi, v. 24, p. 208-218, 2008.

CHAI, J. et al. Effect of pre-slaughter transport plant on blood constituents and meat quality in halothane genotype of NN Large White $\times$ Landrace pigs. Livestock Science, Denmark, v. 127, p. 211-217, 2010.

COCKRAM, M. S. et al. Effect of driver behaviour, driving events and rode type on the stability and resting behaviour 
of sheep in transit. Animal Science, v. 79, p. 165-176, 2004

CORREA, J. A. et al. Effects of different moving devices at loading on stress response and meat quality in pigs. Journal of Animal Science, Champaign, v. 88, p. 4086-4093, 2010.

DALLA COSTA, O. A.; et al. Efeito das condições préabate sobre a qualidade da carne de suínos pesados. Archives Zootecnia, Córdoba, v. 59, n. 227, p. 391- 402, 2010

DALLA COSTA, O. A. et al. Período de descanso dos suínos no frigorífico e seu impacto na perda de peso corporal e em características do estômago. Ciência Rural, Santa Maria, v. 36, n. 5, p. 1582-1588, 2006.

DALLA COSTA, O. A. et al. Modelo de carroceria e seu impacto sobre o bem-estar e a qualidade da carne dos suínos. Ciência Rural, Santa Maria, v. 37, n. 5, p. 14181422, 2007.

DALLA COSTA, O. A. et al. Tempo de jejum dos suínos no manejo pré-abate sobre a perda de peso corporal, o peso do conteúdo estomacal e a incidência de úlcera esofágicagástrica. Ciência Rural, Santa Maria, v. 38, n. 1, p. 199205,2008

EUROPEAN CONVENTION (EC). Council Regulation n.1/2005 (2005): On the protection of animals during transport and related operations and amending Directives 64/432/EEC and 93/119/EC and Regulation (EC) No 1255/97. Official Journal of the European Union, L 3, 22/12/2004, p.0001-0044.

KEPHART, K. B.; HARPER, M.T.; RAINES, C.R. Observations of market pigs following transport to a packing plant. Journal of Animal Science, Champaign, v. 88, p. 2199-2203, 2010.

KIM, D. H.; WOO, J. H.; LEE, C. Y. Effects of stocking density and transportation time of market pigs on their behaviour, plasma concentrations of glucose and stressassociated enzymes and carcass quality. Asian-Australian Journal of Animal Science, Korea, v. 17, p. 116-121, 2004.

KOHLER, R. G.; FREITAS, R. J. S. Qualidade da carne suína após dois tempos de descanso no frigorífico. Archives of Veterinary Science, Curitiba, v. 10, n. 1, p. 89-94, 2005.

LEWIS, N. J.; BERRY, R. J. Effects of season on the behaviour of early-weaned piglets during and immediately following transport. Applied Animal Behaviour Science, v. 100, p. 182-192, 2006.

LI, L. A. et al. Q. Erhualian and Pietrain pigs exhibit distinct behavioral, endocrine and biochemical responses during transport. Livestock Science, Denmark, v.113, p. 169-177, 2008.

LUDTKE, J. V. et al. C. Bem-estar animal no manejo pré-abate e a influência na qualidade da carne suína e nos parâmetros fisilógicos do estresse. Ciência Rural, Santa Maria, v. 42, n. 3, p. 532-537, 2012.

MALENA, M. et al. Comparison of mortality rates in different categories of pigs and cattle during transport for slaughter. Acta Veterinaria Brno, Czech Republic, v. 76, p.109-S116, 2007.

MIRANDA-DE LA LAMA, G. C.; VILLARROEL, M.; MARÍA, G. A. Livestock transport from the perspective of the pre-slaughter logistic chain: a review. Meat Science, Australia, v. 98, p. 9-20, 2014.

MURRAY, C. Reducing losses from farm gate to packer. Advances in Porks Production, Canada, v.11, p.175-180, 2000 .

NANNI COSTA, L. et al. Combined effects of pre-slaughter treatments and lairage time on carcass and meat quality in pigs of different halothane genotype. Meat Science, Australia, v. 61, p. 41-47, 2002.

PÉREZ, M. P. et al. Influence of lairage time on some welfare and meat quality parameters in pigs. Veterinary Record, London, v. 33, p. 239-250, 2002.

PILCHER, C. M. et al. Effects of floor space during transport and journey time on indicators of stress and transport losses of market-weight pigs. Journal of Animal Science, Champaign, p. 2010: 3143, 2011.

RITTER, M. J. et al. Review of Definitions, Incidence, and Economic Impact. The Professional Animal Scientist, Colombi, v. 25, p. 404-414, 2009.

RITTER, M. J. et al. SCHLIPF, J. M.; WOLTER, B. F. Effects of distance moved during loading and floor space on the trailer during transport on losses of market weight pigs on arrival at the packing plant. Journal of Animal Science, Champaign, v. 85, p. 3454-3461, 2007.

RITTER, M. J. et al. Effects of season and distance moved during loading on transport losses of market-weight pigs in two commercially available types of trailer. Journal of Animal Science, Champaign, v.86, p.3137-3145, 2008a.

RITTER, M. J. et al. Effect of floor space during transport of market weight pigs on incidence of transport losses (dead and non-ambulatory pigs) at the packing plant and relationships between transport conditions and losses. Journal of Animal Science, Champaign, v. 84, p. 2856, 2008 b.

SALMI, S. et al. Bayesian meta-analysis of the effect of fasting, transport and lairage times on four attributes of pork meat quality. Meat Science, Australia, v.90, p.584-598, 2012.

SANTANA, A. P. et al. Dosagem de cortisol sanguíneo em suínos submetidos ao manejo pré-abate e insensibilização 
elétrica. Archivos de Zootecnia, Córdoba, v. 58, n. 221, p. 149-152. 2009.

SCHWARTZKOPF-GENSWEIN, K. S. et al. Road transport of cattle, swine and poultry in North America and its impact on animal welfare, carcass and meat quality: A review. Meat Science, Australia, v. 92, p. 227-243, 2012.

SILVEIRA, E. T. F. Manejo pré-abate de suínos e seus efeitos na qualidade da carcaça e carne. Suínos e Cia, São Paulo, v. 6, n. 34, p. 24-33, 2010.

SOUZA, F. F.; CORASSA, A. Principais destinos de suínos para abate produzidos em Mato Grosso. In: CONGRESSO BRASILEIRO DE ZOOTECNIA, 22., 2012, Cuiabá.

Anais... Cuiabá: Congresso Brasileiro de Zootecnia, 2012.

SUTHERLAND, R. W.; DUNNING, P. R.; BAKER, W. M. Amphibian encounter rates on roads with different amounts of traffic and urbanization. Conservation Biology, v. 24, n. 6, p. 1626-1635, 2009.

SUTHERLAND, M. A. et al. The combined effects of transport and food anda water deprivation on the physiology of breeding age gilts. Livestock science, Denmark, v.144, p.124-131, 2012.

WARRISS, P. D. An analysis of data relating to pig carcass quality indices of stress collect in the European Union. Meat Science, Australia, v. 49, p. 137-144, 1998.

WILLIAMS, J. L. et al. Lairage during transport of eighteen-kilogram pigs has an impact on innate immunity and commensal bacteria diversity in the intestines. Journal of Animal Science, Champaign v.86, p.1232-3145, 2008.

Recebido em: 25.08.2015 Aceito em: 18.09.2017 